\title{
A FORMAÇÃO DO BIOTECNODIREITO PELA RECURSIVIDADE CIRCULAR DO SENTIDO JURÍDICO-BIOTECNOLÓGICO: RISCO, DIFERENCIAÇÃO E EVOLUÇÃO
}

\author{
Leonel Severo Rocha ${ }^{1}$ \\ Paulo Roberto Ramos Alves ${ }^{2}$
}

\begin{abstract}
Resumo
O desenvolvimento das biotecnologias proporciona inegáveis desafios ao sistema jurídico que, amparado em uma lógica moderna fundada em certezas, opera sob uma complexidade não condizente com a sociedade contemporânea. A construção da forma geneticamente-aplicável/geneticamente-inaplicável assumida pela biotecnologia redunda na produção comunicativa de riscos biotecnológicos jamais identificados, passando-se a observar a sociedade desde a ótica da possibilidade de ocorrência de desastres pela reiteração da comunicação biotecnológica. O Direito passa a contar com o risco como comunicação juridicamente perceptível, atribuindo a tal comunicação um sentido próprio e, posteriormente, possibilitando a recursividade do discurso jurídicobiotecnológico. Essa recursividade redunda na formação do Biotecnodireito como um subsistema jurídico delimitado pela sua tecnicidade particular ante a assimilação do biorisco. Estabelecido o Biotecnodireito como sistema subdiferenciado no funcional do direito, essa esfera parcial da comunicação jurídica passa a assimilar o risco biotecnológico desde construções internas especialmente delimitadas para tal finalidade.
\end{abstract}

Palavras-chave: Biotecnologia. Evolução. Risco. Teoria Sistêmica.

\section{INTRODUÇÃO}

O presente texto pode ser iniciado a partir de duas noções tradicionais (e duas negações) sobre a evolução da Sociedade e do Direito: a primeira diz respeito à possibilidade de que o sistema social sofra mudanças abruptas, sendo submetido a radicais alterações em suas estruturas independentemente do estado em que estas se

\footnotetext{
${ }^{1}$ Pós-Doutorado pela Universita degli Studi di Lecce, USL, Itália. Coordenador do Programa de Pós-Graduação em Direito da UNISINOS; Bolsista de Produtividade em Pesquisa do CNPq - Nível 1D; Líder do projeto de pesquisa Teoria do Direito e Diferenciação Social na América Latina. E-mail: leonel.rocha@uol.com.br

${ }^{2}$ Doutor em Direito pela Universidade do Vale do Rio dos Sinos - UNISINOS; estágio pós-doutoral em andamento junto ao Programa de Pós-Graduação em Direito da Universidade de Passo Fundo; Bolsista PNPD/CAPES. E-mail: pauloalvess@yahoo.com.br
} 
encontrem. A segunda refere-se à crença no progresso ${ }^{3}$, na respectiva visão a partir da qual a evolução importa em um conjunto de melhorias a serem experimentadas pelos indivíduos e pela própria sociedade.

A tais visões vale contrapor um terceiro argumento tendente a melhor observar a dinâmica evolutiva e que servirá de ponto de partida para as construções posteriormente realizadas: Sociedade e Direito evoluem tão somente a partir de determinadas condições estruturais que lhes permitam a continuidade de suas operações, assegurando sua unidade e existência em condições de dupla contingência, na qual a complexidade é internamente reconstruída na forma de constantes processos seletivos que apenas existem no circuito comunicativo da sociedade e como operações próprias dessa mesma sociedade.

Definida tal premissa, pode-se debruçar com mais vagar na problemática da evolução da sociedade para, em seguida, buscar elementos fundados nessa mesma ótica evolutiva que permitam a emergência de uma especificação diferenciada no âmbito do Direito como produto do próprio Direito. Enquanto forma comunicativa cuja principal característica é a incerteza, o risco biotecnológico constrange a sociedade à formação de racionalidades capazes de operacionalizá-lo em meio a uma contínua produção de complexidade, contingência e novos riscos.

Em outras palavras, a consideração do risco biotecnológico por racionalidades sistêmicas concorrentes acaba por revesti-lo na forma de um atrator sistêmico. Nessa senda, ao valer-se da distinção probabilidade/improbabilidade como forma de gestão da incerteza, a sociedade coloca o risco em um local de evidente visibilidade, tornando-o elemento capaz - independentemente do quão provável ou improvável sua ocorrência seja factível - de orientar os processos de observação e descrição sistêmicas e, dessa maneira, servindo como uma comunicação fundamentalmente relevante para a evolução do sistema social.

A perspectiva evolutiva assentada no risco biotecnológico permite o questionamento sobre o desenvolvimento de racionalidades parciais intrajurídicas, o que se objetiva demonstrar mediante a utilização da Teoria dos Sistemas de Niklas Luhmann como marco teórico do presente ensaio. Vale dizer que a adoção da perspectiva luhmanniana pode promover certa dificuldade ao leitor não familiarizado com a estrutura conceitual da Teoria dos Sistemas, não impedindo, contudo, a compreensão da diferenciação biotecnojurídica adiante demonstrada.

A observação sobre a formação do biotecnodireito é, portanto, o objetivo central do presente ensaio, o qual ampara-se na metodologia sistêmica como forma de se observar - desde a ótica da Ciência - a recursividade dos processos jurídicos, bem como seus ulteriores processos de subdiferenciação como parte de um contexto de regulação dos novos desafios impostos ao sistema social pelo desenvolvimento tecnológico.

\footnotetext{
${ }^{3}$ Luhmann questiona a perspectiva da evolução como progresso, afirmando que "[...] se ha renunciado a valorar la evolución como progreso. Si la evolución se entendiera como progreso se enfrentaría uno a la necesidad de ofrecer una conceptualidad de continuidad lineal, o a desacoplar la evolución de cualquier descripción de un orden originado por la evolución" (LUHMANN, 2005, p. 348)
} 


\section{OBSERVAÇÕES PRELIMINARES SOBRE A EVOLUÇÃO DO DIREITO}

Toda e qualquer alteração nas estruturas sociais depende de um lento e gradativo movimento da sociedade. Mesmo as rupturas revolucionárias mais abruptas verificadas na história ${ }^{4}$ não se mostraram capazes de transformar a realidade da noite para o dia, tornando-se forçoso o reconhecimento quanto à impossibilidade de alteração social a partir de um único centro gravitacional (LUHMANN, 1993, p. 217-218). A evolução social, portanto, relaciona-se intrinsecamente com a continuidade de um movimento comunicativo que é, em última análise, condição de existência dessa mesma sociedade.

Se a evolução é possível, é de ser afirmado que um sistema apenas é capaz de evoluir quando determinados problemas internos promovem um aumento de complexidade desordenada que apenas pode ser resolvida mediante modificações estruturais (LUHMANN, 1991. p. 27). A tal afirmação, Luhmann acrescenta uma importante observação quando sublinha que o agravamento de problemas internos não significa que os problemas sistêmicos produzam por si próprios suas soluções ou que, ainda, apontem para eventual teleologia no âmbito das operações sistêmicas. Antes, a determinação dos problemas diante do reconhecimento da insuficiência estrutural sistêmica é o que permite a busca por soluções que apenas serão possíveis a partir de novas percepções internamente construídas.

A perspectiva luhmanniana, portanto, rompe com a máxima darwiniana da sobrevivência do mais apto. Alicerçado na autopoiese de Maturana e Varela, Luhmann parte do pressuposto de que a sobrevivência não depende de uma melhor aptidão à adaptação, mas, sim, à própria capacidade de adaptação enquanto requisito para a autopoiese. Um sistema é adaptado ou não é. Ainda que frágil - sob outros pontos de observação - um sistema autopoiético sempre será adaptado ao seu meio circundante, não sendo possível defender uma busca por adaptação (LUHMANN, 1991, p. 25). Necessariamente o sistema produzirá continuamente aqueles elementos que asseguram a continuidade dessa adaptação.

A impossibilidade de melhor ou pior adaptação do sistema ao seu meio circundante passa a ser o marco central de uma teoria que tenha pretensão de explicar a sociedade desde a perspectiva de sua evolução. A sociedade, portanto, não encontra como condição de sua continuidade - e evolução - a melhor adaptação ao seu meio. Quando se observa o sistema social na forma da unidade da diferença entre comunicação e nãocomunicação, como consequência lógica o problema da melhor ou pior adaptação é transposto para o problema da continuidade de suas operações autopoiéticas ou, em outras palavras, para a capacidade do sistema em permanentemente reproduzir seus elementos constitutivos ante os influxos originados em seu entorno.

Dito de forma mais direta, se a sociedade existe na forma de um sistema autopoiético comunicativamente omniabarcador, é razoável reconhecer que essa mesma sociedade é também adaptada ao seu

${ }^{4}$ Cite-se como exemplos a Revolução Francesa de 1789 e a Revolução Russa de 1917. 
meio. A partir de tal constatação, a discussão que emerge refere-se à continuidade das operações sociais. Ao ser comunicativamente produzido, o sistema social reclama uma constante produção de comunicações como condição para a continuidade de sua autopoiese (LUHMANN, 2007, p. 339). A sociedade reclama a produção de sempre renovadas comunicações - o que se dá mediante a produção de diferença -, cujos critérios para sua identificação repousam sob a ótica constituída com base na atribuição de sentido (LUHMANN, 1998, p. 87) que os sistemas funcionais parciais apresentam.

Nessa ótica, evolução significa a conservação/reprodução do sistema a partir de uma multiplicação daqueles pressupostos sob os quais torna-se possível o desenvolvimento de determinada ordem sistêmica (LUHMANN, 2007, p. 328). Um sistema autopoiético - e, por isso, necessariamente adaptado - conduz a uma contínua produção de complexidade como requisito para suas operações posteriores. A historicidade sistêmica mostra-se como elemento intrinsecamente relacionado à sua capacidade evolutiva. Quanto mais complexo um sistema for, maior será sua capacidade de reação diante de influxos externamente produzidos. Essa afirmação terá consequências drásticas para a internalização do risco biotecnológico e a formação de uma esfera comunicativa diferenciada no Direito, conforme será adiante observado.

Teubner bem observou o Direito quando partiu do pressuposto de que seus processos evolutivos não se dão de forma teleológica, orientando-se finalisticamente, mas sim teleonomicamente, no qual se constrói a realidade a partir da continuidade das operações sistêmicas possíveis em determinado momento, isto é, a partir da combinação de certos programas bem sucedidos, da eliminação de outros que tenham se mostrado falhos, na recombinação de programas onde a manutenção inalterada não se mostre possível, etc. (1989, p. 98). Nessa perspectiva, o conceito de evolução não importa em melhoria ou progresso. A evolução, passa a se relacionar com os processos de diferenciação por meio dos quais o sistema adapta-se à realidade do momento, tornando-se capaz de produzir respostas de acordo com a binariedade específica que o caracteriza.

Teubner elenca três elementos centrais de uma teoria da sociedade com vistas a uma observação teórica dos processos de evolução jurídica, identificando-os pela possibilidade de interação entre variação, seleção e retenção, pela combinação entre desenvolvimento ontogenético e filogenético e pela co-evolução entre Direito, Sociedade e outros sistemas parciais (1989, p. 104). O primeiro elemento - variação, seleção e retenção - referese à constante interação jurídica a partir da diferença endógeno/exógeno. O Direito é construído internamente e apenas direito produz direito (LUHMANN, 2005, p. 106). Essa perspectiva conduz à necessária compreensão de que a estrutura jurídica (normas, processos, dogmática) produz uma realidade própria, interna ao sistema do Direito. A endogenia jurídica, na ótica de Teubner, é influenciada por fatores exógenos (sociais), havendo uma constante troca entre Direito e Sociedade. 
Os fatores endógenos e exógenos do Direito funcionam mediante sucessivas operações de variação, seleção e retenção, garantindo à estrutura normativa (leis) a função de variação, à estrutura procedimental (processos) a função de seleção e à estrutura dogmática a função de retenção (TEUBNER, 1989, p. 104). Essa mesma perspectiva é encontrada em Luhmann quando demonstra que a evolução do Direito opera de modo circular diante dos influxos do entorno. Aqui, a evolução se dá quando o sistema responde às perturbações com variação interna, seleciona operações relevantes e estabiliza a comunicação, tornando a impulsionar outras inovações, circularmente (LUHMANN, 2005, p. 339).

A endogenia jurídica pressupõe o equilíbrio de um constante paradoxo sistêmico definido pela abertura do Direito por meio de seu fechamento. A afirmação de Teubner sobre a produção do Direito pelo Direito não pressupõe o retorno às raízes positivistas oitocentistas, mas torna claro que "o Direito não é determinado por si próprio ou por normas superiores, mas sim pela sociedade e por sua evolução - entendida como aumento de complexidade social" (SCHWARTZ, 2014, p. 107) e, consequentemente, pela possibilidade de assimilação dessa complexidade pelas estruturas internas do sistema jurídico que, mediante seu código, as processará, permitindo a evolução do Direito e da Sociedade.

Ao condicionar a evolução do Direito a operações de variação, seleção e retenção, Teubner igualmente passa a reconhecer o desenvolvimento ontogenético e filogenético como um segundo elemento nos processos evolutivos. Tal elemento permite se observar que "a combinação do desenvolvimento ontogenético e filogenético no Direito, ou seja, a interrelação entre processo jurídico e cultura jurídica, deve ser vista como uma interacção entre dois ciclos comunicativos" (TEUBNER, 1989, p. 122), fazendo com que o Direito - por meio da centralidade dos tribunais - produza decisões baseadas em decisões anteriormente tomadas e que se afirmarão, de igual maneira, como ponto de partida para outras decisões, possibilitando o desenvolvimento autorreferencial do sistema jurídico.

Se, por um lado, o Direito combina processos interativos entre filogênese e ontogênese no sentido de que tais relações possibilitam complexas interações comunicativas intrajurídicas, viabilizando trocas entre processo e cultura jurídica, bem como se, por outro lado, o Direito harmoniza operações internas de variação, seleção e retenção, um terceiro elemento pode ser visto a partir dessas interaçães: a inegável co-evolução entre Direito e Sociedade. Esse terceiro elemento informa que, no cenário moldado a partir do reconhecimento de processos co-evolutivos, "a selecção das mudanças e inovações no direito não é apenas imputável à autopoiesis do próprio sistema jurídico, mas também [...] à autopoieisis doutros subsistemas sociais e da própria sociedade" (TEUBNER, 1989, p. 123) enquanto sistema comunicativo omniabarcador.

Diante de tais considerações é possível questionar, com Luhmann, se no interior de um sistema autopoiético (Direito) que se desenvolve no âmbito interno de outro sistema autopoiético (sociedade) é possível 
a emergência de níveis recursivos de comunicações jurídicas que permitam seu enclausuramento autorreferencial e, com isso, fomentem processos de diferenciação no interior de um sistema já funcionalmente diferenciado. Em outras palavras, questiona-se se dentro de sistemas autopoiéticos é possível a existência de outros sistemas autopoiéticos (LUHMANN, 2005, p. 304) como resultado e, paradoxalmente, como condição de novos processos evolutivos.

A essas constatações, e a partir delas, poder-se-ia acrescentar algumas observações atinentes ao próprio risco biotecnológico no âmbito do Direito, notadamente o fato de que aquele torna-se tema comunicativo no interior do sistema jurídico, identificando-se mediante a forma direito/não-direito a partir da produção de decisões desde o centro do sistema, bem como pela produção legislativa periférica com referência ao tema (LUHMANN, 1990, p. 160-163). Por outro lado, a realidade e historicidade do sistema, já transformadas pela assimilação de tal comunicação mantêm-se em movimento, tendo no risco das biotécnicas um elemento que contribui para a circularidade das operações jurídicas.

No tocante aos aspectos filogênicos e ontogênicos do sistema, pode-se notar que o risco biotecnológico, quando tematizado processualmente, induz o sistema a assimilá-lo sob a forma de comunicação jurídica. Dito de outro modo, enquanto comunicação assimilada pela via processual, o risco biotecnológico passa a se relacionar, em um primeiro momento, com a capacidade de percepção jurídica quanto à necessidade de seu enfrentamento, possibilitando, em um segundo momento, sua cristalização temporal sob a forma de estrutura sistêmica, o que se traduz pela formação de expectativas normativas (LUHMANN, 1983, p. 109), como pode ser observado no próprio desenvolvimento da Lei no $11.105 / 2005$, na qual criou-se o Conselho Nacional de Biossegurança (CNBS), reestruturou-se a Comissão Técnica Nacional de Biossegurança (CTNBio), previu a Política Nacional de Biossegurança, entre outras disposições.

Ora, se a evolução do Direito depende também de critérios racionalmente construídos desde outros pontos de observação, é razoável afirmar que uma possível gestão do risco biotecnológico - inclusive por ser um problema originado além das fronteiras jurídicas - passa pela possiblidade de que a realidade construída pelo sistema do Direito observe juridicamente outras realidades sociais. Em síntese, a evolução do sistema jurídico depende da igual evolução de outros subsistemas sociais e de constantes trocas comunicativas entre si.

Enquanto a autonomia do Direito é uma realidade perseguida desde as primeiras bandeiras que anunciavam o constitucionalismo, essa mesma autonomia, se isoladamente considerada, redunda no risco do fechamento e, via de consequência, no problema do enclausuramento sistêmico para com a sociedade. Logo, se "o sistema fechado não é possível" e "o sistema aberto é inútil" (ROCHA, 2005, p. 38), importando por um lado, no solipsismo cognitivo sistêmico e, por outro, na desdiferenciação em relação ao seu entorno, a continuidade das 
operações autopoiéticas e a própria evolução do sistema dependem de uma racionalidade que reconheça que a evolução jurídica se dá de forma paralela à evolução dos demais sistemas sociais.

É certo que a evolução da sociedade não pode ser prevista ou condicionada. Ao valer-se da capacidade de diferenciar-se funcionalmente, o sistema social constrói racionalidades sistêmicas que, umas para as outras, afirmam-se como entorno. O sistema jurídico, dessa maneira, assimila a comunicação biotecnológica produzindo uma assimetrização temporal a partir de sua permanente reconstrução com base na distinção interior/exterior.

\section{O RISCO BIOTECNOLÓGICO COMO ATRATOR JURÍDICO: SOBRE A FORMAÇÃO DA DIFERENÇA JURIDICAMENTE-CONDICIONANTE/JURIDICAMENTE- CONDICIONADO}

Evolução, diferenciação, indeterminação. Tais elementos emergem diafanamente quando se observa a sociedade desde uma perspectiva autopoiética, logo, uma possível gestão jurídica do risco biotecnológico passa pela própria evolução da sociedade e do Direito. Sendo a evolução observada como um processo que se relaciona intrinsecamente com a habilidade da sociedade em resolver problemas por ela própria criados, é razoável que o risco seja percebido como um elemento de evidente importância naqueles processos de diferenciação funcional que caracterizam a evolução social.

Claro está que o Direito não é um sistema que opera de forma determinística. O enfretamento do Direito sob sua consideração como sistema autopoiético exclui qualquer possibilidade de que este opere sob a chancela de premissas deterministas ou teleológicas. A sociedade e seus subsistemas parciais operam sob uma constante produção de complexidade que, sob a ótica de outros observadores, afirma-se como complexidade desordenada, encontrando alguma lógica a partir da atribuição do sentido binário que tão somente o observador é capaz de realizar.

Foi a capacidade da sociedade em ultrapassar um modelo segmentário para um modelo funcionalmente diferenciado a variável mais importante da evolução social (LUHMANN, 1987, p. 218), a qual permitiu sua autodescrição a partir da ótica autopoiética e, descrevendo-se como tal, também identificou-se na forma de um sistema dotado de autonomia, diferença, repetição e historicidade. A estrutura social atual, pois, permite a análise do fenômeno jurídico como um sistema capaz de produzir e manter a si próprio, bem como dotado da função específica de assegurar expectativas normativas (LUHMANN, 1983, p. 109).

É exatamente a análise do Direito como sistema autopoiético que se traduz em alternativa para uma possível gestão do risco biotecnológico, o que se dá a partir de uma constante possibilidade de variação daqueles elementos e necessidades internamente relevantes para o sistema. O risco biotecnológico, quando percebido mediante a distinção direito/não-direito, pode ser observado na forma de um atrator juridicamente 
condicionante, constrangendo o sistema à evolução a partir de situações que não mantém qualquer relação teleológica ou determinística, mas sim com a deriva estrutural presente na história da autopoiese sistêmica.

Objetivando minimizar a possibilidade de mal entendidos, há de se chamar a atenção para a expressão juridicamente condicionante, bem como realizar algumas aclarações teóricas necessárias à sua melhor compreensão. Antes de mais nada, vale ressaltar que o sistema jurídico pode ser visto como um sistema caótico. O caos afirma-se como o conjunto de fatores de instabilidade no qual pequenas perturbações tornam-se capazes de produzir grandes mudanças no futuro do sistema (PRIGOGINE, 2002, p. 12), situação sobre a qual Prigogine define que o aumento de energia de um sistema - o que, na esfera social pode-se vislumbrar sob o incremento de complexidade por meio da incessante produção comunicativa - conduz à um igual aumento do número de trajetórias aleatórias passíveis de serem seguidas pelo sistema, tornando-o caótico (PRIGOGINE, 2002, p. 58).

Dito de outra maneira, a incessante produção daqueles elementos que caracterizam o sistema conduz a um incrivel incremento de complexidade internamente produzida, impondo ao futuro sistêmico uma grande quantidade de trajetórias possíveis. Quanto mais complexo um sistema social, maiores as suas possibilidades de decisão, logo, a não-linearidade dos sistemas caóticos conduz a um grande aumento entrópico que impõe, em tese, a incapacidade de se prever, pressupor ou determinar as trajetórias a serem seguidas pelo sistema, inclusive na seara das probabilidades (PRIGOGINE, 1996, p. 81-83).

Ante a indeterminação do caos desenvolveu-se, pela física moderna, o conceito de atrator para definir um comportamento ou conjunto de comportamentos para o qual um sistema caótico é direcionado (LORENZ, 1963, p. 130-132). A evolução do sistema encontra em um atrator um ponto para o qual o sistema é impulsionado, tomando certo caminho ao invés de outro. Tal conceito, se utilizado juntamente à noção de deriva natural viabilizada na seara biológica por Maturana e Varela (1992, p. 41), possibilita que a indeterminação dos sistemas autopoiéticos seja mantida, contudo, acena para o reconhecimento de situações comportamentais de outras esferas sociais que podem ser assumidas internamente de acordo com os critérios e interesses do próprio Direito, impulsionando a evolução.

Quando se fala do risco biotecnológico como uma comunicação que viabiliza a formação de uma multiplicidade de estados internos em diversos sistemas sociais, pode-se perceber a aptidão do Direito em observar juridicamente outras observações sociais, bem como de construir um duplo critério evolutivo: primeiro, a construção de estruturas jurídicas viabilizadas a partir da observação de comunicações de risco; segundo, a colocação da comunicação jurídica produzida como elemento capaz de causar ressonâncias em outros sistemas sociais, como a Ciência ou a Economia.

Nas duas situações o risco biotecnológico figura como um atrator sistêmico. Ao mesmo tempo em que o Direito é impulsionado à formação de novas racionalidades jurídicas - inclusive com processos internos de 
diferenciação - ele igualmente produz diferença a partir da operacionalização do risco. Tal significa que o risco biotecnológico afirma-se como elemento juridicamente condicionante no sentido de que permite que o sistema evolua mediante sua consideração. $\mathrm{O}$ atrator do sistema nesse caso não é o risco biotecnológico em si mesmo, mas aqueles comportamentos que passam a ser esperados a partir do horizonte de sentido juridicamente possível no âmbito sistêmico.

Pode-se afirmar que o risco biotecnológico constitui-se na forma de uma comunicação que, quando observada juridicamente, conduz à formação de um conjunto de comportamentos sistêmicos específicos. Ao se afirmar como uma comunicação capaz de promover ressonâncias (LUHMANN, 1989, p. 19-21) no sistema jurídico, o risco biotecnológico pode ser visto na forma de um atrator estranho, o qual não permite uma condição de determinação do estado posterior do sistema, mas, ao contrário, a observação jurídica do risco oscila de acordo com o conteúdo da irritação sofrida pelo Direito e, de igual maneira, pelo estado do sistema em um dado momento.

A instabilidade do sistema permite que o Direito seja permanentemente reconstruído a partir de suas próprias necessidades, erigindo horizontes de sentido jurídico diante de situações indeterminadas espacial e temporalmente. Essa constatação torna visível que, se o caos é a realidade do Direito, a única ordem viável é aquela construída a partir dessa incapacidade de previsão ou determinação do estado posterior do sistema. A ordem jurídica, em seu sentido de organização e estruturação, apenas é possível distante de qualquer determinismo, pois "nenhuma medida, nenhum cálculo leva estritamente a um ponto, à consideração de uma trajetória 'única'; estaremos sempre diante de 'conjuntos' de trajetórias" (PRIGOGINE, 2002, p.51). Tal conjunto de trajetórias, entretanto, pode ser influenciado diante de certas circunstâncias. É certo que "a história do sistema, como um todo, pode levar, por certas 'bifurcações' nas decisões, a estados de estabilidade” (TEUBNER, 2005, p. 37), sendo construída a partir de limites decisórios e cognitivos que condicionam o futuro e a evolução. O enfrentamento do tema a partir da consideração de atratores juridicamente condicionantes produz uma reviravolta quanto às condições sistêmicas para a evolução da capacidade regulatória do Direito.

Pois bem. No mesmo momento em que a evolução jurídica pode ser observada desde o risco biotecnológico como elemento conducente à formação de atratores juridicamente condicionantes, os quais impulsionarão o sistema do Direito a novas formas de auto-observação e autodescrição, também produz observações quando a construção de atratores juridicamente condicionados. Enquanto aquele, como visto, se afirma como um conjunto de comportamentos assumidos pelo sistema a partir da consideração do risco das biotécnicas, este reflete a forma pela qual se faz visível o rompimento para com a regulação da sociedade por meio do Direito e a consequente assunção de formas de regulação indireta. 
Fático é o reconhecimento quanto à crise de efetividade que assola a prática jurídica. Essa crise de regulação é denunciada, sob as lentes sistêmicas, entre outros, por Rocha (2009, p. 37) e Carvalho (2013, p. 4647), conduzindo à percepção - desde a ótica da Ciência - de que, por um lado, o Direito enclausura-se operativamente, tornando-se impossível sua determinação por outros sistemas, bem como sua intervenção direta em outras esferas sociais, impossibilitando a regulação direta da sociedade e de seus subsistemas pelo Direito. Além dessa crise regulatória externa, o sistema jurídico também enfrenta problemas internos, relacionados com a incapacidade da dogmática jurídica em assimilar novos problemas produzidos pela sociedade contemporânea, $\mathrm{o}$ que se dá em razão de sua operacionalização mediante uma lógica unicamente condicional que não mais é compatível com a hipercomplexidade do momento atual (CARVALHO, 2013, p. 50-51).

Poder-se-ia dizer le Roi est mort, vive le Roi $^{5}$ em relação ao direito regulatório ou ainda, vê-lo sob a perspectiva de uma morte anunciada como o fez Teubner parafraseando a observação literária de García Márquez. A morte anunciada do direito regulatório exige novas perspectivas jurídicas para o enfrentamento dos problemas produzidos pela sociedade sob a forma de uma regulação contextual, a qual pode ser pensada a partir de um intervencionismo capaz de criar condições necessárias para o desenvolvimento dos atratores desejados (TEUBNER, 2005, p. 39).

É nesse contexto que a consideração da comunicação jurídica na forma de atratores juridicamente condicionados permite a regulação. Se a regulação direta entre diferentes esferas sociais não é possível, uma alternativa para tal problema é a construção de condições para uma regulação indireta ou reflexiva entre Direito e sociedade. Nesse aspecto, concordando com Teubner, é possível que a comunicação jurídica seja direcionada de modo a causar perturbações em outras esferas sociais, constituindo-se na forma de um atrator firmado desde a perspectiva jurídica. Ainda que arriscada, tal estratégia permitiria que verdades juridicamente construídas fossem assimiladas sob os pontos de observação de outras esferas sociais, possibilitando não uma regulação pelo Direito, mas uma regulação indireta que se construiria a partir do Direito.

Quando se fala em atratores juridicamente condicionantes e atratores juridicamente condicionados temse em perspectiva exatamente a alocação da distinção interno/externo no interior jurídico. Internamente a evolução jurídica torna-se condicionada àquelas necessidades produzidas pelo risco biotecnológico enquanto produto social, desde que tal risco seja percebido pelo sistema jurídico, o que possibilita a alteração nas estruturas do Direito pelo próprio Direito. Externamente, o sistema torna-se capaz de influenciar comportamentos de outros observadores desde construções orientadas à produção de perturbações específicas a serem observadas por outras racionalidades sociais.

\footnotetext{
5 “O Rei está morto. Viva o Rei." Expressão cunhada por ocasião da coroação de Carlos VII, da França após o falecimento do monarca anterior, Carlos VI, a qual designa a transferência dos poderes do monarca falecido ao soberano recém proclamado. vol. 08, nº. 04, Número Especial. Rio de Janeiro, 2015.pp. 2449-2473 
Ressalte-se que a distinção interno/externo ou, de forma mais incisiva para o presente escopo, a diferença condicionante/condicionado apenas é possível desde o próprio Direito. O condicionamento jurídico não é possível desde fora do sistema ou promovido por qualquer outra autoridade que não a do próprio sistema jurídico. Tal constatação impõe o reconhecimento quanto à internalização da distinção interno/externo na elaboração daquelas operações que são particulares ao sistema do Direito.

Assim sendo, é a realidade do Direito que possibilita a discussão quanto aos atratores condicionantes/condicionados, viabilizando que sua prática seja direcionada desde a consideração do risco biotecnológico: internamente, como critério evolutivo; externamente, como possibilidade de regulação, ainda que esta segunda hipótese se caracterize, de igual maneira, como um produto internamente produzido. A formação da distinção condicionante/condicionado depende, contudo, daquelas condições apenas possibilitadas pela historicidade do sistema do Direito. A visualização do risco biotecnológico como atrator evolutivo condicionante/condicionado não soluciona a problemática da contingência da distinção geneticamenteaplicável/geneticamente-inaplicável, mas, ao contrário, afirma a possibilidade de que, diante da não solução do problema, existam caminhos passíveis de construção pelo Direito.

As estruturas sociais tornam-se factíveis apenas a partir de uma canalização que vai de uma operação a outra, permitindo que a referência à comunicação deixe um campo aberto para novas possibilidades e, com isso, exponha as estruturas sociais à evolução (LUHMANN, 2007, p. 339). Logo, se a evolução é possível apenas a partir de uma referência ampla a um universo de comunicações selecionáveis, o risco biotecnológico como atrator permite que esse mesmo universo mantenha-se como um horizonte decisório, porém, ao mesmo tempo acena para possibilidades de trajetórias que, caso seguidas, vincularão o futuro do sistema.

No plano da práxis jurídica pode-se observar como atratores juridicamente condicionantes aqueles comportamentos das estruturas jurídico-dogmáticas tendentes a solucionar problemas relacionados à biotecnologia ${ }^{6}$ quando colocadas em funcionamento diante de perturbações sofridas pelo Direito que, a partir de sua operacionalização, permite a criação de novas condições estruturais que conduzem a referência do sistema àquelas operações futuras possíveis no campo da gestão do risco biotecnológico. Internamente, o risco biotecnológico como atrator juridicamente condicionante permite que a recursividade das operações realizadas pelo sistema do Direito seja influenciada por aqueles critérios possíveis a partir da distinção legislação/jurisdição. Ou seja, os mecanismos que asseguram a funcionalidade do Direito a partir de sua unidade distintiva apontam para a igual possibilidade de produção de comunicações que possam vir a ser identificadas autonomamente no interior do sistema sob o símbolo de uma codificação binária ainda mais restritiva e parcial.

\footnotetext{
${ }^{6}$ Cite-se exemplificativamente as Ações Civis Públicas, ações que objetivem a tutela específica do risco, perícias ambientais, termos de ajustamento de conduta, entre outros.
} 
Por outro lado, a comunicação jurídica deve ser capaz de produzir ressonâncias em seu entorno ou, melhor dito, nos sistemas presentes em seu entorno. A segunda forma assumida pelos atratores evolutivos é possível desde a remessa das perturbações externas ao plano interno, sua operacionalização jurídica e, reflexamente, a resposta jurídica a tais perturbações. Logo, se é possível partir-se da lógica evolutiva para se observar a formação do sentido jurídico dos riscos biotecnológicos, é também possível que a mesma lógica evolutiva permita a formação de atratores juridicamente condicionados que, quando utilizados pelo Direito, apontam para a dupla finalidade da regulação indireta e da evolução sistêmica.

É na bifurcação entre duas realidades comunicativas que emerge a possibilidade de se observar a formação sistêmica de uma esfera restritiva de sentido no interior do Direito. Ao contrário da comunicação técnica, no campo jurídico a indeterminação não permite qualquer planificação racionalmente orientada ou uma utilização teleológica. Nesse sentido, partindo-se do pressuposto do Direito como sistema autopoiético, sua reprodução é possível apenas com referência à própria indeterminação, havendo, no dizer de Nicola, a certeza quanto à sua existência, porém, incerteza quanto ao seu conteúdo (1987, p. 238).

A incerteza quanto ao conteúdo do direito futuro é o que assegura a liberdade evolutiva do sistema. Ao se observar o risco biotecnológico como uma comunicação capaz de se amoldar sob a distinção juridicamentecondicionante/juridicamente-condicionado, esta passa a atuar como uma comunicação que permeia o interior sistêmico e assegura a evolução por meio do tratamento jurídico que passa a ser possibilitado por meio da mencionada diferença.

Os atratores condicionantes/condicionados, portanto, relacionam-se com aqueles comportamentos esperados a partir da interação entre Direito e sociedade, bem como pela consideração do risco e sua assimilação jurídica. Quando o sistema reage a determinada perturbação, há a reconstrução interna daqueles pressupostos jurídicos úteis ao processamento da perturbação em questão. Em outras palavras, a percepção do risco faz com que o sistema atue sob uma tríplice estratégia cognitiva que envolve processos de variação, seleção e retenção, como definiu Teubner (1989, p. 104).

Essa tríplice estratégia permite que o Direito perceba, assimile e estruture internamente o risco biotecnológico por meio de seus instrumentos dogmáticos e, ao mesmo tempo, conduz o sistema a uma realidade até então inexistente. Ao buscar estruturar internamente possibilidades de gestão de risco, o Direito se autoconstrói e, logo, ao perceber o risco biotecnológico e criar estratégias para sua gestão, igualmente coloca-se na linha de partida para novas aquisições evolutivas. Eis a circularidade.

O contexto autopoiético na qual se insere o sistema do Direito conseguiu, com base em tais estratégias, construir uma realidade jurídica na qual o risco biotecnológico pôde ser objeto de tematização comunicativa. Tais estratégias podem ser observadas, por exemplo, pela formação dos princípios da precaução e prevenção e sua 
aplicação como forma de gestão de risco, pela irritação política promovida pela Lei no $11.105 / 2005$, bem como pela atuação dos tribunais mediante a constatação e assimilação do risco biotecnológico desde o centro do sistema do Direito.

Ao entrarem em funcionamento, esses mecanismos passam a assumir comportamentos específicos tendentes a assegurar a gestão dos riscos advindos da distinção geneticamente-aplicável/geneticamenteinaplicável. Além disso, ao se observar tais mecanismos como elementos que, a seu modo, direcionarão o sistema para determinada trajetória, tem-se sua caracterização vinculada à formação de atratores evolutivos que possuem nos comportamentos jurídicos próprios à gestão do risco biotecnológico seu ponto de convergência.

A partir daí, o problema que se coloca diz respeito à reiteração da comunicação jurídica quando em referência a questões relacionadas à biotecnologia. Sabe-se que a recursividade das operações sociais permite o desenvolvimento de racionalidades sistêmicas parciais capazes de cumprir funções específicas (LUHMANN; DE GIORGI, 1993, p. 327). Como já referido, tais funções são cumpridas por esferas comunicativas restritivas que adquirem autonomia diante da sociedade e passam a operar com base em uma referência binária à suas estruturas e operações. A situação se agrava, porém, quando se reconhece o desenvolvimento de comunicações parciais no interior de sistemas funcionais autônomos, impondo a estes uma subdiferenciação interna.

A reiteração de comunicações que se amoldam sob a forma do risco biotecnológico fornece ao Direito uma complexidade tal que coloca o sistema em funcionamento no intuito de incrementar sua própria complexidade interna para a redução da complexidade de seu entorno. Sendo um sistema reflexivo, no momento em que o Direito se ocupa com o risco biotecnológico ele passa a produzir uma reiteração comunicativa capaz de permitir níveis de recursividade tais que direcionam a comunicação à formação intrasistêmica de distinções específicas. Com isso, ainda que a comunicação do sistema do Direito mantenha sua referência primária à distinção direito/não-direito, a recursivização daquelas comunicações jurídicas com referência à biotecnologia passam a formar uma cadeia autorreferencial capaz de diferenciar-se de outras comunicações também jurídicas.

\section{A ESPECIFICAÇÃO INTERNA DO SENTIDO JURÍDICO DA BIOTECNOLOGIA E A FORMAÇÃO DO BIOTECNODIREITO}

A evolução do Direito é condicionada à possibilidade de que o sistema constantemente reaja às perturbações originadas na sociedade. Desde tal perspectiva, o Direito reage de acordo com sua codificação binária objetivando conhecer situações de seu entorno, o que lhe é possibilitado apenas pelo recurso à elaboração interna daqueles critérios que lhe permitirão a cognição a partir da contínua reconstrução dos elementos perceptíveis em seu ambiente, conforme já anteriormente alinhado. 
Foi a reiteração da comunicação jurídica a partir de um circuito comunicativo autorreferencial que permitiu, inicialmente, a distinção entre Direito e Política, evidenciando, em um segundo momento, o desenvolvimento de subdiferenciações internamente produzidas, redundando em processos de diferenciação na diferenciação, isto é, a produção de diferenças intrasistemicamente relevantes para o Direito. Tal estratégia redundou na formação de racionalidades jurídicas ainda mais restritivas, como a especificação inicial entre direito público e privado e, posteriormente, a produção de novas diferenças a partir de subsequentes especificações comunicativas, a que a dogmática jurídica nomeou como ramos do direito ou disciplinas dogmáticas?.

Ao reagir diante do risco biotecnológico o sistema do Direito passa a estabelecer uma relação recursiva na qual determinadas estratégias de gestão encadeiam-se com outras estratégias anteriormente realizadas, permitindo que se desenvolva uma referência específica à comunicação biotecnológica de risco. O sentido jurídico atribuído ao risco biotecnológico, portanto, passa a depender dessa reiteração comunicativa que ocorre no interior do sistema, ou seja, no mesmo momento em que o Direito reproduz sua diferença constitutiva (direito/não-direito), igualmente produz outras diferenças perceptíveis apenas desde o seu interior.

Quando se fala na evolução do Direito, igualmente posiciona-se o observador diante de uma contínua ciranda decisório-comunicativa onde determinadas estruturas sociais (e jurídicas) tornam-se factíveis ou são descartadas, sedimentando-se uma realidade que, apesar de aparentemente aleatória ou arbitrária, torna-se a realidade da sociedade em um dado momento. Alcover bem identifica essa característica ao afirmar que, durante o processo evolutivo da sociedade experimenta novas estruturas que são confirmadas ou descartadas, demonstrando que comunicações tidas como caóticas gradativamente vão se transformando em probabilidade estruturada, permitindo a evolução social (ALCOVER, 1993.p. 88).

É possível visualizar o processo de diferenciação sistêmica como a reprodução intrasistêmica da diferença constitutiva entre sistema e entorno. Luhmann salienta que a diferenciação passa a ser compreendida como um processo reflexivo e recursivo próprio da construção dos sistemas sociais. Assim, a principal função a ser cumprida pelos sistemas funcionais, incluindo-se o Direito, é o paradoxal aumento/redução da complexidade de seus respectivos ambientes, o que conduz à possibilidade de igual estruturação de sistemas menores com base em sua própria seletividade, sendo tal processo reproduzido internamente pelos subsistemas (LUHMANN, 1998, p. 73-74). Assim visto, os sistemas sociais aumentam sua complexidade interna - por meio de estratégias particulares a cada observador - objetivando construir experiências que lhes permitam compreender seu meio circundante.

\footnotetext{
${ }^{7}$ Pode-se definir como uma disciplina dogmática aquela que parte da consideração de determinadas premissas arbitrárias como vinculantes para seu estudo. Assim, as questões dogmáticas são regidas por um limite comunicativo identificado por Luhmann como a "la non-negabilità dei punti di partenza di catene argomentative" ou a inegabilidade dos pontos de partida das cadeias argumentativas, sendo esta vista como aquela ordem vinculante que se torna aceita e não negada pelos juristas. A dogmática, contudo, não cria uma esfera de agrilhoamento para o pensamento, mas, ao contrário, proporciona um aumento de liberdade para com a observação da realidade normativa, assegurando que o conhecimento dogmático faça emergir, de modo paradoxal, as incertezas que pretensamente buscou ocultar (LUHMANN, 1978. p. 43-45).
} 
Logo, a diferenciação funcional pode ser compreendida como um dos fatores evolutivos da sociedade, pois estabilizam-se resultados operativos e, dessas operações, elaboram-se condições para novos processos evolutivos (LUHMANN, 1998, p. 88), observando-se tal processo igualmente no âmbito interno dos sistemas parciais. É inegável que os subsistemas reproduzirão constantemente diferença, ora atuando via a estratégia da reentry (BROWN, 1973. p. 69-73.) para assegurar a paradoxal reprodução de sua unidade operativa e de diferenças internamente perceptíveis, ora diferenciando-se operativamente por meio da construção de sistemas organizacionais e, de forma reflexa, possibilitando a formação de constantes sistemas de interação (LUHMANN, 2010, p. 116-119; MANSÍLLA, 2010.p. 16).

Sendo a pretensão ora proposta referente à possibilidade de formação de uma racionalidade comunicativa parcial tendente a enfrentar a problemática do risco biotecnológico, deve-se partir do pressuposto de que, ao mesmo tempo em que o Direito se enclausura autorreferencialmente, construindo condições para seus processos cognitivos e operativos, ele também produz comunicações, uma vez que a produção comunicativa por meio de suas organizações - é o que assegura a continuidade das operações autopoiéticas do sistema.

Tais comunicações - identificadas primariamente como jurídicas por meio da distinção direito/nãodireito - forçosamente encontrarão ulteriores formas de especificação intrasistêmica, isto é, dada a sua reflexividade, o resultado das operações levadas adiante pelo Direito poderá se amoldar sob formas distintivas possibilitadas por sua reiteração comunicativa, o que sinaliza para a viabilidade em se reconhecer o desenvolvimento de uma rede de comunicações intrajurídicas que, mesmo permanecendo jurídicas, serão passíveis de uma distinção secundária no interior do sistema.

Ao enfrentar o problema da formação do sentido jurídico-ambiental, Carvalho bem salientou que a noção jurídica de meio ambiente é produzida a partir de processos de auto-observação possíveis apenas com referência ao reingresso da diferença sistema/ambiente ecológico no interior sistêmico, formando-se, assim, a constituição identitária do Direito ambiental. O sentido jurídico de meio ambiente, nessa perspectiva, torna-se realidade por meio do imbricamento comunicativo daqueles processos intrasistêmicos próprios do Direito (legislação, doutrina e jurisprudência), o que possibilita a condensação do sentido jurídico-ambiental (CARVALHO, 2009.p. 33).

Vale dizer, a esse respeito, que meio ambiente e biotecnologia comunicam-se de forma evidente. Basta se pensar nos problemas relacionados ao risco ecológico pela elaboração ou utilização de determinado OGM, por exemplo. Antes de prosseguir, contudo, algumas distinções fazem-se necessárias ao se falar de direito ambiental e biotecnologia. Muito embora meio ambiente e biotecnologia sejam comunicações com uma evidente proximidade, estas distanciam-se desde a perspectiva do observador quando se intenta analisar a formação de uma rede comunicativa autônoma no interior do sistema jurídico. A esse respeito pode-se retomar e aprofundar 
algumas características da distinção natureza/biotecnologia, identificando as seguintes razões pelas quais o tratamento jurídico do risco biotecnológico diferencia-se do tratamento jurídico do risco ambiental, não se confundindo com este:

1. O risco biotecnológico torna-se a condição primária, em certos casos, para a produção de um risco ambiental secundário. Nesse aspecto, o risco biotecnológico afirma-se como o vértice formativo de uma segunda espécie de risco (ambiental) que apenas existirá na simultaneidade da primeira espécie, ou seja, o biorisco assume a forma ambiental quando assim tematizado sistemicamente.

2. A biotecnologia diferencia-se da natureza (LUHMANN, 1996, p. 187), razão pela qual, quando observada desde a perspectiva da possibilidade de desastres, afirma-se como um desastre antropogênico especificado como uma subforma do risco tecnológico (CARVALHO; DAMACENA, 2013, p. 26-27). Logo, toda e qualquer ressonância ambiental do risco biotecnológico afirma o duplo problema da reconstrução social da natureza e sua reinserção no ambiente natural (entorno social), conduzindo ao reconhecimento de que a biotecnologia é um produto comunicativo que, ao mesmo tempo, reinsere-se no meio ambiente, passando a reproduzir-se mediante uma diferenciação artificial no meio natural.

3. A incerteza biotecnológica apenas existe quando em referência a processos decisórios (sociais), podendo-se falar apenas de riscos. Já a incerteza ambiental pode assumir a igual forma do perigo, eis que sob tal vértice o meio ambiente comporta a não-decisão como realidade. Enquanto aquela pode ser vista como um produto eminentemente social, este existe no entorno da sociedade. $\mathrm{O}$ meio ambiente, assim, não é um produto comunicativo em si, eis que existe independentemente da sociedade. Logo, ao passo em que o risco biotecnológico é a realidade que exsurge a partir da reiteração da comunicação biotecnológica, o meio ambiente comporta variáveis não-comunicativas que se amoldam sob a forma do perigo, não sendo possível geri-lo juridicamente na amplitude de situações que não se enquadram no horizonte decisório.

4. Ainda que a referência comunicativa a questões ambientais seja necessária para sua tematização, a natureza surge, se desenvolve e perece de forma autônoma, ao contrário dos desenvolvimentos da biotecnologia que, por sua vez, exige uma forte imbricação de conhecimentos organizacionais (socialmente produzidos) para a produção de ressonâncias junto à sociedade.

5. Enquanto resíduo comunicativo de processos (bio)técnicos (sociais), a incerteza biotecnológica pode ser objeto de planificações racionais objetivando-se a identificação de níveis de risco a serem suportados pela sociedade. Já na esfera ambiental qualquer planificação mostra-se possível apenas com referência à percepção social do meio ambiente, permanecendo intangíveis outros aspectos naturais não observados comunicativamente. 
Quando o Direito internaliza a comunicação ambiental estão pressupostos processos cognitivos que caracterizam o observador como capaz de observar apenas o que é possível observar, excluindo-se dessa observação aquilo que não pode ser observado (LUHMANN, 1998. p. 63). Logo, o Direito apenas pode assimilar comunicações enquanto elementos socialmente produzidos. O conceito jurídico de meio ambiente é internalizado por meio da distinção que o sistema jurídico realiza sobre aquelas comunicações sociais que dizem o que é meio ambiente. Ou seja, o Direito não pode acessar o que não é comunicação, a não ser quando a nãocomunicação (nesse caso o meio ambiente) torna-se um evento comunicativo. $\mathrm{O}$ risco biotecnológico, ao contrário, é essencialmente comunicação. Ele não existe senão em referência à própria sociedade e, por isso, pode ser objeto de planificações racionais em seus mais diversos níveis - da responsabilidade dos cientistas (CAMBRÓN, 2003, p. 3-4) à gestão dos riscos organizacionais -, o que impõe à racionalidade do Direito uma grande complexidade a ser internalizada e juridicamente assimilada.

Pois bem. Feitas tais distinções pode-se retornar à questão central da internalização jurídica do sentido biotecnológico. Está claro que o risco biotecnológico é uma comunicação que impõe ao sistema do Direito uma grande complexidade a ser assimilada. Ao reproduzir-se socialmente, a incerteza biotecnológica passa a constranger o Direito à sua observação e internalização, o que ocorre por meio dos citados processos de variação, seleção e retenção e das trocas cognitivas entre sistemas sociais distintos. Ainda que o risco não possa ser por si mesmo uma estrutura social, ele fomenta a formação de estruturas capazes de geri-lo, atuando no âmbito intrajurídico na forma de um atrator juridicamente condicionante.

A aquisição do sentido jurídico-biotecnológico, portanto, é possível mediante uma série de estratégias sistêmicas utilizadas pelo Direito mediante uma dupla referência: de forma endógena, quando atua mediante seus processos, estruturas e operações próprias; de forma exógena, quando observa seu entorno objetivando aprender a conhecer situações que até então não fazem parte de sua realidade. Assim, pode-se reconhecer nessa dupla referência aqueles processos coevolutivos entre Direito e sociedade denunciados por Teubner (1989, p. 123), os quais apontam para a possibilidade de evolução (LUHMANN, 2007, p. 444).

A autonomização da comunicação jurídica é vista como o primeiro passo para ulteriores especificações no interior do sistema do Direito. A codificação direito/não-direito é o requisito mínimo para a identificação do sistema jurídico como dotado de autonomia, repetição e diferença e, por isso, capaz de se assegurar sua continuidade autopoiética por meio da construção de mecanismos de assimilação e gestão do risco biotecnológico. Partindo-se da premissa inicial do Direito como sistema social individualizado binariamente, recai-se em um segundo passo evolutivo, qual seja, o reconhecimento da circularidade das operações do sistema no sistema. 
O Direito seleciona aquelas comunicações que lhes são necessárias para sua autorreprodução. Ao observar juridicamente a biotecnologia, o sistema lê aquelas perturbações de acordo com sua possibilidade cognitiva, fomentando o reingresso da distinção sistema/ambiente no próprio sistema jurídico e, com isso, internalizando a comunicação biotecnológica e transmudando-a para a forma jurídica. Em outras palavras, o sistema atribui o sentido jurídico às comunicações biotecnológicas, fazendo com que estas adquiram relevância dentro do sistema.

A formação do sentido jurídico-biotecnológico pode ser observada a partir da assimilação jurídica dos riscos produzidos pela comunicação amoldada sob a distinção geneticamente-aplicável/geneticamenteinaplicável. Nesse contexto, é visível o movimento sistêmico no sentido da construção desse sentido parcial por meio da constante atuação dos tribunais e da produção legislativa, os quais vêm a produzir uma diferença internamente perceptível ante as perturbações produzidas pela reiteração da comunicação biotecnológica e sua constante produção de riscos.

A partir de acontecimentos como os acidentes em Chernobyl, Three Miles Island e Bhopal, a sociedade passou a assimilar o risco como uma comunicação diferenciada do perigo, a qual remete à intrínseca possibilidade de danos diante de processos decisórios. Com essa perspectiva iniciaram, a partir da década de 1990, fortes processos de irritação jurídica fomentados por movimentos ecológicos e pela retórica do medo (LUHMANN, 1996. p. 15-16) quanto ao risco biotecnológico, os quais foram irradiados para diversos sistemas sociais culminando na formação de observações sistêmicas sobre comunicações de risco.

Juridicamente esse movimento autopoiético é visível desde o desenvolvimento de mecanismos internacionais reconhecendo a relevância da atenção jurídica diante dos avanços da biotecnologia, como a Declaração da Conferência das Nações Unidas sobre o Meio Ambiente Humano, adotada em Estocolmo em 16 de junho de 1972; o Relatório Brundtland, elaborado pela Comissão Mundial sobre Meio Ambiente e Desenvolvimento em 1987; a Declaração do Rio sobre Meio Ambiente e Desenvolvimento, adotada no Rio de Janeiro em junho de 1992, bem como a Convenção da Diversidade Biológica (CDB) também elaborada por força da Eco-92; o acordo suplementar conhecido como Protocolo de Cartagena sobre Biossegurança, além do Protocolo Suplementar de Nagoya-Kuala Lumpur sobre Responsabilidade e Reparação, adotado em 15 de Outubro de 2010, na cidade de Nagoya.

As irritações proporcionadas pelo forte movimento internacional reconhecendo a relevância jurídica de questões atinentes aos reflexos e riscos da biotecnologia viabilizaram, no Brasil, a assimilação dessas comunicações por meio de uma série de irritações políticas, podendo-se citar o artigo 225, inciso III da Constituição Federal, que definiu a fiscalização das entidades dedicadas à pesquisa e manipulação de material genético; a Lei no 6.938/1981, que instituiu a Política Nacional do Meio Ambiente; a Lei no 11.105/2005 (Lei de Biossegurança), que revogou a 
Lei no 8.974/1995; a Lei no 9.456/1997, que instituiu a Lei de Proteção de Cultivares, além da Medida Provisória no 2.186-16/2001, que regulamentou o inciso II do $\$ 1^{\circ}$ e o $\$ 4^{\circ}$ do art. 225 da Constituição, os artigos. $1^{\circ}, 8^{\circ}$, alínea "j", 10, alínea "c", 15 e 16, alíneas 3 e 4 da Convenção sobre Diversidade Biológica, que dispôs sobre o acesso ao patrimônio genético e deu outras providências.

Ainda, pode-se identificar a construção interna do sentido biotecnológico por meio dos decretos de números 6.041/2007 (instituiu a Política de Desenvolvimento da Biotecnologia), 2.519/1998 (promulgou a Convenção sobre Diversidade Biológica, assinada no Rio de Janeiro, em 05 de junho de 1992.), 5.950/2006 (regulamentou o art. 57-A da Lei no 9.985, de 18 de julho de 2000, estabelecendo limites para o plantio de organismos geneticamente modificados nas áreas que circundam as unidades de conservação), 4.680/2003 (regulamentou o direito à informação quanto aos alimentos e ingredientes alimentares destinados ao consumo humano ou animal que contenham ou sejam produzidos a partir de organismos geneticamente modificados), além dos Decreto Legislativo no 2/1994 (aprovou o texto da Convenção sobre Diversidade Biológica) e das Resoluções do Conselho Nacional de Saúde (CNS) no 196/1996 (aprovou as diretrizes e normas regulamentadoras de pesquisas envolvendo seres humanos) e no 251/1997 (aprovou normas de pesquisa envolvendo seres humanos para a área temática de pesquisa com novos fármacos, medicamentos, vacinas e testes diagnósticos).

Além da irritação político-legislativa derivada das mencionadas normas, as quais contribuíram para a autopoiese do sistema do Direito mediante sua percepção e assimilação jurídicas, os tribunais igualmente passaram a reconhecer o risco biotecnológico em diversas decisões ${ }^{8}$, podendo-se mencionar o paradigmático caso da soja Roundup ready como a primeira demanda jurídica envolvendo organismos geneticamente modificados no Brasil.9 Isso permitiu a convergência da comunicação jurídica para a temática do risco e, consequentemente, à

\footnotetext{
${ }^{8}$ Vide, por exemplo, TRF1, Apelação Cível no 199834000276820. Quinta Turma, Relatora: Des. Selene Maria de Almeida. Julgado em 28.06.2004. D.J. de 01.09.2004; TRF1, Apelação Cível no 200740000004716. Quinta Turma, Relatora: Des. Selene Maria de Almeida. Julgado em 24.10.2012. D.J. de 07.11.2012; TRF1, Embargos Infringentes na Apelação Cível no 199834000276820. Terceira Seção, Relator: Des. Jirair Aram Meguerian. Julgado em 25.03.2014. D.J. de 23.05.2014; TRF3, Agravo de Instrumento $n^{\circ}$ 00485852020074030000. Quarta Turma, Relatora: Des. Mônica Nobre. Julgado em 27.03.2008. D.J. de 24.06.2008; TRF4, Apelação Cível no 200071010004456. Terceira Turma, Relator: Des. Carlos Eduardo Thompson Flores Lenz. Julgado em 29.08.2005. D.J. de 05.10.2005.

${ }^{9}$ Em 10 de junho de 1998, a empresa Monsanto do Brasil Ltda. encaminhou à CTNBio pedido de instauração de processo objetivando a emissão de parecer técnico conclusivo, previsto no art, 2a, X, do Decreto 1.752/1995, sobre os níveis securitários da soja Roundup Ready, cuja principal característica é a resistência ao herbicida glifosato (comercialmente conhecido como Roundup e também produzido e comercializado pela norte-americana Monsanto) decorrente da inserção de genes da bactéria agrobacterium tumefaciens. Após instauração do processo, o Instituto Brasileiro de Defesa do Consumidor (IDEC) ajuizou medida cautelar inominada objetivando a determinação judicial de não autorizar o plantio sem que houvesse a regulamentação da matéria e o respectivo Estudo de Impacto Ambiental. Em seguida, o IDEC, o Greenpeace e outras associações ingressaram com Ação Civil Pública (ACP) (autuada junto à 6a Vara Federal do Distrito Federal sob no 1998.34.00.027681-8), a qual foi julgada procedente em 10 de agosto de 1999 sob o amparo no princípio da precaução. Após recurso de apelação da Monsanto nos autos da Ação Civil Pública, o Tribunal Regional Federal da 1a Região julgou o mesmo procedente, autorizando-se o cultivo da soja Roundup Ready. Para maiores detalhes vide LOPEZ, 2010.p. 217-218; HEBERLÊ, 2010.p. 110-111; REALE, 2001.p. 109-125.
} 
produção de diferença mediante a estratégia cognitiva possibilitada pela via processual. Tal conjunto de operações demonstra a combinação entre processos filogenéticos e ontogenéticos do sistema, viabilizando a identificação de uma rede interna de comunicações jurídicas passíveis de identificação sob a forma comunicativa ora denominada Biotecnodireito.

Partindo-se do pressuposto da sociedade (e do Direito) como sistema mundial (LUHMANN; DE GIORGI, 1993, p. 69), é impossível se furtar à referência quanto à formação de um sentido jurídicobiotecnológico igualmente na seara daquelas organizações descentralizadas sob o ponto de vista jurídico-estatal. Em outras palavras, além da autorreferência da comunicação jurídico-biotecnológica no marco estatal e internacional, deve-se ter presente o fenômeno da policontexturalidade ${ }^{10}$, a qual conduz para a formação de racionalidades jurídicas independentes da centralidade estatal, conforme denunciado, entre outros, por Teubner (2003. p. 18-19), Neves (2009, p. 33) e Rocha (2005, p. 45).

Ao mesmo tempo em que uma diferença jurídico-biotecnologicamente relevante é produzida pelos tribunais, essa comunicação é potencializada por uma série de atores jurídicos descentralizados e não vinculados imediatamente à figura do Estado. Refira-se, a esse respeito, o desenvolvimento de comunicações identificadas sob a distinção direito/não-direito produzidas por grandes conglomerados econômicos e organizações transnacionais (a exemplo da lex mercatoria), a crescente solução de conflitos por órgãos arbitrais, bem como a reprodução do sentido jurídico-biotecnológico pelas mesmas organizações responsáveis pela amplificação comunicativa do biorisco, as quais, ao assimilarem determinadas perturbações jurídicas por meio da distinção direito/não-direito o que ocorre por meio de contratos, termos de ajuste de conduta, formas de publicidade, entre outros -, produz uma paradoxal reprodução de riscos e do sentido jurídico-biotecnológico.

Ao se falar em uma instância diferenciada de outras comunicações jurídicas, o Biotecnodireito pode ser observado na forma de um fechamento autônomo de operações jurídicas - identificáveis sob o signo binário direito/não-direito - que assegura à comunicação jurídico-biotecnológica uma recursividade específica. Dito de outro modo, as operações realizáveis pelo Direito com referência à comunicação biotecnológica tornam-se passíveis de reconhecimento intrajurídico mediante ulteriores distinções perceptíveis desde a ótica interna do sistema.

Por assim dizer, as operações do Biotecnodireito necessariamente farão referência àqueles critérios internamente construídos por meio de suas operações anteriores, reconstruindo a diferença entre o sentido da comunicação biotecnológica e a comunicação jurídico-biotecnológica por meio de constantes operações de reentry, ou seja permitindo que a diferença direito/não-direito seja reenviada ao interior do sistema de modo a

\footnotetext{
${ }^{10}$ A noção de policontexturalidade designa a fragmentação de sentido verificada na sociedade contemporânea. Por sociedade policontextural é possível identificar a existência de múltiplas formas de observação concorrentes - e contraditórias - para a realidade.
} 
construir novos horizontes de sentido jurídico-biotecnológico. $\mathrm{O}$ reingresso da distinção na distinção permite a delimitação de ulteriores formas jurídicas, constrangendo o sistema à evolução condicionada aos seus pressupostos autopoiéticos.

Significa dizer que, de forma reflexiva, a imagem jurídica da biotecnologia passa a produzir outras comunicações - agora sob o símbolo operativo do sistema do Direito - que tornarão a se unir circularmente com a mesma comunicação originária, produzindo um enclausuramento jurídico-biotecnológico, o que se traduzirá na própria autorreferência das operações do sistema e, com isso, gradativamente reforçará aquela rede de comunicações que culminará na formação interna do Biotecnodireito.

\section{CONSIDERAÇÕES FINAIS}

O conjunto de comportamentos jurídicos atrelados ao risco biotecnológico passa a produzir operações circulares, cuja reiteração redunda na formação de um sentido parcial à comunicação resultante da juridicização do risco biotecnológico. Além da percepção jurídica do risco biotecnológico e sua utilização na forma de um atrator sistêmico, a abertura do Direito às perturbações biotecnológicas redunda na formação de uma forte especificação de sentido jurídico, encontrando-se a reiteração circular de uma comunicação parcial intrasistêmica.

Produzida diretamente a partir da observação jurídica daquelas observações científicas e econômicas da técnica, o sentido jurídico parcial atribuído à comunicação biotecnológica resulta na formação interna de uma especificação funcional semiautônoma. Por obvio, ainda que existam estruturas jurídicas autônomas no sistema jurídico - a exemplo dos ordenamentos jurídicos extra-estatais -, a delimitação de uma esfera comunicativa voltada à gestão do biorisco não pode ser percebida desde uma perspectiva imediatamente autônoma, mas como uma comunicação construída a partir de um balizamento que ultrapassa o mero sentido parcial para se amoldar sob uma forma intrajurídica própria. Logo, pôde-se perceber a formação de uma racionalidade intrajurídica especialmente formatada para a atenção jurídica do risco biotecnológico, sendo esta superespecificação interna de sentido jurídico reconhecida na esfera do que pode ser identificado como Biotecnodireito.

Quando a circularidade das operações jurídicas confunde-se especificamente com operações voltadas à gestão do risco das biotecnologias, pode-se notar o desenvolvimento do Biotecnodireito como um subsistema produzido imediatamente pelo próprio Direito. Em outras palavras, a formação do sentido jurídico e seu semienclausuramento fomentam ulteriores formas de diferenciação, permitindo uma diferenciação-nadiferenciação ou, ainda, a especificação de um sistema-no-sistema, cujas operações tornam-se voltadas fundamentalmente à assimilação jurídica do risco biotecnológico permitindo, com isso, a construção de novos elementos hábeis à gestão de risco em um modelo de sociedade extremamente plural, complexo e arriscado. 


\title{
THE FORMATION OF BIOTECHLAW BY CIRCLE RECURSION OF LEGAL AND BIOTECHNOLOGICAL SENSE: RISK DIFFERENTIATION AND EVOLUTION
}

\begin{abstract}
The advances in biotechnology provides undeniable challenges to the legal system, which sustained by a modern logic founded on certainties, operates under a complexity not consonant with the contemporary society. The construction of genetically applicable / genetically inapplicable method undertaken by the biotechnology, results in the communicative production of biotechnology risks which have never been identified, now observing the society from the perspective of a possibility of disaster by the reiteration of biotechnology communication. Law now count on the risk as legal evident communication, assigning to such communication a specific meaning and subsequently allowing recursiveness to the legal and biotechnological discourse. This recursiveness results in the formation of Biotechlaw as a legal subsystem enclosed by its particular technicality before the assimilation of biohazardous. Established Biotechlaw as sub-distinguished system in the functional of law, the partial sphere of legal communication starts to assimilate the biotechnological risk from internal constructions specially defined for this purpose.
\end{abstract}

Keywords: Biotechnology. Evolution. Risk. Systemic theory.

\section{REFERENCIAS}

ALCOVER, Pilar Giménez. El derecho en la teoria de la sociedad de Niklas Luhmann. Barcelona: J.M. Bosh Editor, 1993.

BROWN, George Spencer. Laws of form. New York: Bantam Books, 1973.

CAMBRÓN, Ascensión. La superación del derecho por la biotecnología. In: Colóquio Internacional - Direito e Justiça no Século XXI. Coimbra: Centro de Estudos Sociais. mai. 2003. p. 3-4. Disponível em: <http://www.ces.uc.pt/direitoXXI/comunic/Ascencion Cambron.pdf > Acesso em 10 dez. 2014.

CARVALHO, Délton Winter. A formação sistêmica do sentido jurídico do meio ambiente. Revista de Estudos Constitucionais, Hermenêutica e Teoria do Direito (RECHTD). São Leopoldo: Unisinos. v. 1. n. 1. jan./jun. 2009.

Dano ambiental futuro: a responsabilização civil pelo dano ambiental. 2. ed. Porto Alegre: Livraria do Advogado, 2013.

CARVALHO, Délton Winter. DAMACENA, Fernanda Dalla Libera. Direito dos desastres. Porto Alegre: Livraria do Advogado, 2013.

DE GIORGI, Raffaele. Direito, democracia e risco: vínculos com o futuro. Porto Alegre: Sérgio Antônio Fabris, 1998.

Direito, tempo e memória. São Paulo: Quartier Latin, 2006. 45-54.

O risco na sociedade contemporânea. Sequência, Florianópolis: Fundação Boiteux, n. 28, jun., 1994. p. 
FERRAZ JUNIOR, Tércio Sampaio. Introdução ao estudo do direito: técnica, decisão, dominação. 4. ed. São Paulo: Atlas, 2003.

FOERSTER, Heinz von. For Niklas Luhmann: "how recursive is communication?". In FOERSTER, Heinz von. In: Understanding understanding: essays of cybernetics and cognition. New York: Springer-Verlag, 2003. p. 305323.

HEBERLÊ, Antônio. Transgressão transgênica: a história dos transgênicos no sul do Brasil. Pelotas: Embrapa Clima Temperado, 2010.

LORENZ, Edward Norton. Deterministic nonperiodic flow. Journal of the atmospheric sciences, Boston: American Meteorological Society. v. 20, n. 2. mar. 1963.p. 130-141

LOPEZ, Teresa Ancona. Princípio da precaução e evolução da responsabilidade civil. São Paulo: Quartier Latin, 2010.

LUHMANN, Niklas. A estabilidade instável. In: SILVA, Juremir Machado da. O pensamento do fim de século. Porto Alegre: L\&PM, 1993. p. 218-219. Entrevista concedida a Juremir Machado da Silva, realizada em Porto Alegre, em setembro de 1990.

A posição dos tribunais no sistema jurídico. Ajuris, Porto Alegre, Ajuris, n. 49, ano XVII, jul., 1990.

¿Cómo se pueden observar estructuras latentes? In: WATZLAWICK, Paul; KRIEG, Peter. El ojo del observador: contribuciones al constructivismo. Barcelona: Gedisa, 1998. p. 60-72.

Complejidad y modernidad: de la unidad a la diferencia. Madrid: Trotta, 1998.

El derecho de la sociedad. 2. ed. México: Herder/Iberoamericana, 2005.

Ecological communication. Chicago: The University of Chicago Press, 1989.

La ciencia de la sociedad. Ciudad de México: Universidad Iberoamericana/Iteso/Anthropos, 1996.

La comprensión de los sistemas por los sistemas. In: LUHMANN, Niklas; SCHORR, Karl Eberhard. El

sistema educativo (problemas de reflexión). Guadalajara: Universidad de Guadalajara/Universidad Iberoamericana/ITESO, 1993.

La costituzione come acquisizione evolutiva. In: ZAGREBELSKY, Gustavo; PORTINARO, Pier Paolo; LUTHER, Jörg. Il futuro della costituzione. Torino: Einaudi, 1996. (LUHMANN, Niklas. A Constituição como aquisição evolutiva. Tradução livre feita por Menelick de Carvalho Netto, Giancarlo Corsi e Raffaele de Giorgi).

La sociedad de la sociedad. Ciudad de México: Universidad Iberoamericana/Herder Editorial, 2007.

La teoría de la diferenciación social. Revista de Occidente, Madrid: Fundación Ortega Y Gasset, n. 74-75, jul-ago., 1987. p. 210-220.

Límites de la comunicación como condición de evolución. Revista de Occidente, Madrid: Fundación Ortega Y Gasset, n. 118, mar., 1991.p. 23-40.

Observing re-entries. Graduate Faculty Philosophy Journal, Nova Iorque: The New School. v. 16, n. 2, 1993. P. 485-498.

Organización y decisión. Mexico: Herder Editorial/Universidad Iberoamericana, 2010.

Organización y decisión. autopoiesis, acción y entendimento comunicativo. Barcelona/México/Santiago de Chile: Anthropos Editorial/Universidad Iberoamericana/Pontificia Universidad Católica de Chile, 2005.

¿Puede la sociedad moderna evitar los peligros ecológicos? Argumentos. Coyoacán: Universidad Autônoma Metropolitana. n. 24. set. 1996.p. 7-18.

Sistema giuridico e dogmatica giuridica. Bologna: Il Mulino, 1978.

Sociologia do direito. v. I. Rio de Janeiro: Tempo Brasileiro, 1983.

Sociología del riesgo. México: Triana Editores, 1998. 
LUHMANN, Niklas. DE GIORGI, Raffaele. Teoría de la Sociedad. Guadalajara: Universidad de Guadalajara/Universidad Iberoamericana/Iteso, 1993.

MAGALHÃES, Juliana Neuenschwander. O uso criativo dos paradoxos do direito. In: ROCHA, Leonel Severo. Paradoxos da auto-observação: percursos da teoria jurídica contemporânea. Curitiba: JM, 1997. p. 243-277.

MANSÍLLA, Darío Rodríguez. Introducción. La teoría como pasión. In: LUHMANN, Niklas. Organización y decisión. Mexico: Herder Editorial/Universidad Iberoamericana, 2010. p. 9-21.

NEVES, Marcelo. Transconstitucionalismo. São Paulo: Martins Fontes, 2009.

NICOLA, Daniela Ribeiro Mendes. Estrutura e função do direito na teoria da sociedade de Luhmann. In: ROCHA, Leonel Severo. Paradoxos da auto-observação: percursos da teoria jurídica contemporânea. Curitiba: JM, 1997.p. 221-242.

PRIGOGINE, Ilya. As leis do caos. São Paulo: Unoesp, 2002.

O fim das certezas: tempo, caos e natureza. São Paulo: Editora da Universidade Estadual Paulista, 1996.

REALE, Miguel. Legitimidade do Plantio de Soja Transgênica. In: Revista dos Tribunais. São Paulo: RT. v. 90, n. 789. jul. 2001.p. 109-125.

ROCHA, Leonel Severo. Da epistemologia jurídica normativista ao construtivismo sistêmico. In ROCHA, Leonel Severo; SCHWARTZ, Germano; CLAM, Jean. Introdução à teoria do sistema autopoietico do direito. Porto Alegre: Livraria do Advogado, 2005. p. 9-47.

O direito na forma de sociedade globalizada. In: ROCHA, Leonel Severo. Epistemologia jurídica e democracia. 2. ed. São Leopoldo: Unisinos, 2003. p. 185-201.

Observações sobre a observação luhmanniana. In ROCHA, Leonel Severo, KING, Michael; SCHWARTZ, Germano. A verdade sobre a autopoiese no direito. Porto Alegre: Livraria do Advogado, 2009. p. $11-40$.

ROCHA, Leonel Severo. DUARTE, Francisco Carlos. O Direito e o tempo social. In: ROCHA, Leonel Severo; DUARTE, Francisco Carlos (Coord.). A construção sociojurídica do tempo. Curitiba: Juruá, 2012. p. 15.33.

ROMESÍN, Humberto Maturana; MPODOZIS, Jorge. Origen de las especies por medio de la deriva natural. Santiago: Museo Nacional de Historia Natural, 1992.

ROMESÍN, Humberto Maturana; VARELA, Francisco. A árvore do conhecimento: as bases biológicas da compreensão humana. São Paulo: Palas Athena, 2001.

De máquinas e seres vivos: autopoiese - a organização do vivo. 3. ed. Porto Alegre: Artes Médicas, 1997.

SCHWARTZ, Germano. Direito \& Rock: o BRock e as expectativas normativas da Constituição de 1988 e do Junho de 2013. Porto Alegre: Livraria do Advogado, 2014.

TEUBNER, Gunther. Autopoiesis in law and society: a rejoinder to Blankenburg. Law \& Society Review: Law and Society Association: Salt Lake City. v. 18, n. 2, 1984. p. 291-301.

Direito, sistema e policontexturalidade. Piracicaba: Unimep, 2005.

El derecho como sistema autopoiético de la sociedad global. Bogotá: Universidad Externado de Colombia, 2005. 
O direito como sistema autopoiético. Lisboa: Fundação Calouste Gulbenkian. 1989.

Trabalho enviado em 24 de agosto de 2015.

Aceito em 02 de outubro de 2015. 